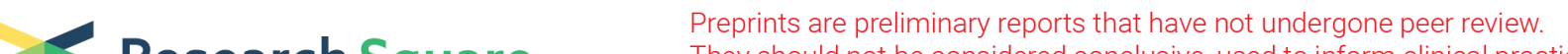 $\begin{array}{ll}\text { Research Square } & \text { They should not be considered conclusive, used to inform clinical practice, } \\ \text { or referenced by the media as validated information. }\end{array}$
}

\section{What is the Impact of Infrapopliteal Endovascular Intervention on Free Flap Survival in Diabetic Foot Reconstruction?}

Duy Quang Thai

Ajou University https://orcid.org/0000-0002-7216-2514

Dong Hwan Lee

Ajou University Hospital

Woo Beom Lee

Ajou University Hospital

Hyung Min Hahn

Ajou University Hospital

II Jae Lee ( $\nabla$ i00325@live.co.kr)

Ajou University Medical College https://orcid.org/0000-0002-9478-6969

Research article

Keywords: Diabetic Foot, Peripheral Arterial Disease, Endovascular Intervention, Percutaneous

Transluminal Angioplasty, Free Flap

Posted Date: October 7th, 2020

DOl: https://doi.org/10.21203/rs.3.rs-84452/v1

License: (c) (i) This work is licensed under a Creative Commons Attribution 4.0 International License. Read Full License

Version of Record: A version of this preprint was published on January 11th, 2021. See the published version at https://doi.org/10.1186/s13018-020-02173-9. 


\section{Abstract}

Background The combination of endovascular intervention and microvascular free flap transfer has been effectively used for the chronic ischemic wounds of lower limb. This study aimed to indicate the influence of angioplasty on the free flap survival in diabetic foot ulcer reconstruction.

Methods A retrospective research was conducted of 46 diabetic patients with chronic ulcer of the foot. All the patients underwent the free flap reconstruction because of their non-healing wound with tendon or bone exposure. Patient's demography, clinical data related to vascular status, vascular intervention, free flap transfer procedure were collected. Flap survival rate was compared between the group of severe arterial stenosis and non-severe group and between the different revascularization result groups as well.

Results The average was $56.2 \pm 10.8$ years with 14 men (30.4\%) and 32 women (69.6\%). All of 23 patients $(50 \%)$ who had severe infrapopliteal arterial stenosis underwent endovascular intervention. The final result of the pedal arch was type 1 in $13 / 23$ patients (56.5\%), type $2 A$ and $2 B$ in $7 / 23$ and 2/23 patients respectively and type 3 in only one patient. Total flap necrosis was in 5 cases $(10.9 \%)$, marginal necrosis in 4 cases (8.7\%) and wound dehiscence in 4 cases (8.7\%). There was no significant difference of flap loss between the severe arterial stenosis patients and non-severe arterial stenosis patients. In severe arterial stenosis group, after endovascular intervention, patients with type 1 of pedal arch had a significantly lower rate of total flap necrosis compared to the others. There was also no association between using of revascularized recipient artery and flap survival.

Conclusions Our study revealed the crucial of quality of pedal arch on free flap survival. The PTA should aim to re-establish the complete pedal arch to increase the rate of wound healing as well as the flap success.

\section{Background}

Diabetic foot ulcer consequence of neuropathy and peripheral arterial disease (PAD) is a common complication of diabetes mellitus (DM). Although diabetic defects are mostly able to treat with conservative modalities or simple debridement and suture, a broad and deep ulcer with bone and tendon exposure is more challenging. The extensive diabetic foot ulcer with PAD often leads to major amputation that not only reduces the quality of life but also increase the mortality rate [1]. There are some studies successfully employed local flap or skin graft, however generally salvaging these ischemic limbs without a strong and reliable flap is limited [2, 3]. In 1985, Brigg et al. first combined the revascularization surgery and free tissue transfer to reconstruct the ischemic lower limb [4]. This combination led a trend in diabetic foot reconstruction in which the arterial bypass surgery played a crucial role to increase the blood supply for distal limbs as well as the free flap. Since the introduction of endovascular intervention with several advantages, this method has replaced the bypass surgery to be the primary indication in critical limb ischemia management [5]. Subsequently, numerous investigations of the combination between preoperative angioplasty and microvascular free flap surgery have been carried out. However, the 
influence of percutaneous transluminal angioplasty (PTA) to the free flap success in diabetic patients has not been well established. Our purpose in the present study is to illuminate this matter.

\section{Methods}

A retrospective study was carried out on 46 diabetic patients who underwent foot defects reconstruction by the free flap in Plastic and Reconstructive Department of Ajou University Hospital from 2011 to 2019. Patients were indicated free flap because of their soft tissue defects with exposure of bones and/or tendons that could not be treated by the other simple procedures. Only patients with DM foot ulcers were included in the study. Patients with incomplete records would be also excluded. All the patients were followed up for more than 6 months.

Clinical data were collected via the patient's chart, radiographs of the lower extremity, preoperative and postoperative photographs. These data were patient's age, sex, medical histories, characteristics of the wounds, vascular status, detail of vascular intervention, characteristic of the flap, flap outcomes, complications and follow-up information.

Continuous variables were expressed as mean \pm standard deviation. Chi-square test and Fisher's exact test were employed to analyze categorical variables. P-value $<0.05$ was considered statistically significant. Statistical analyses were performed with IBM SPSS 20.0.

\section{Treatment procedure}

Treatment started with careful assessment of the wound as well as the status of the vessels. If there were any symptoms of infection such as redness, swelling or hot skin, debridement would be indicated. Simultaneously, patient would be further evaluated for vasculopathy and neuropathy, in case that we did not palpate or identify the distal pulsation of infragenicular arteries with handheld Doppler. Patients routinely underwent pre-operative CT angiography for evaluation of the infrapopliteal arterial condition and flap planning as well. According to the results of CT angiography, the severity of stenosis was graded as shown in Table 1. Patients who had grade 4 and 5 stenosed vessels were called the severe PAD group. All the patients of this group underwent PTA for increasing the distal perfusion for the foot via the pedal arch. Post-angioplasty pedal arch was classified as shown in Table 2. Free flap transfer surgery was performed once there was at least one patent blood flow to the foot and the recipient base was clean. 
Table 1

Grading of severity of arterial stenosis [6]

\begin{tabular}{|ll|}
\hline Grade & Criteria \\
\hline 0 & Normal patency \\
\hline 1 & Mild (stenosis of less than $25 \%$ of diameter) \\
\hline 2 & Moderate (stenosis of $25 \%-50 \%$ of diameter) \\
\hline 3 & Moderate severe (stenosis of $50 \%-75 \%$ of diameter) \\
\hline 5 & Severe (stenosis of $75 \%-99 \%$ of diameter) \\
\hline
\end{tabular}

Table 2

Classification of pedal arch [7]

\begin{tabular}{|ll|}
\hline Types & Blood supply \\
\hline Type 1 & From both DPA and plantar artery \\
\hline Type 2A & Only from DPA \\
\hline Type 2B & Only from plantar artery \\
\hline Type 3 & Both DPA and plantar arteries occluded \\
\hline
\end{tabular}

\section{Results}

A total of 46 foot-defects in 46 diabetic patients were covered with free flaps, the patient's background data were shown in Table 3. The average age of patients was $56.2 \pm 10.8$ years (range from 37 to 80 years old) 14 men (30.4\%) and 32 women (69.6\%). Of 46 patients, eight patients (17.4\%) were with end-stage renal disease (ESRD) and $17(37 \%)$ patients were active smokers. The most common location was forefoot $(n=15)$ followed by heel and dorsum $(n=11$ and $n=10$ respectively), the remainder located in lateral malleolar $(n=6)$, plantar $(n=2)$ and ankle $(n=2)$ (Table 3.). 
Table 3

Patient's demographic detail

\begin{tabular}{|c|c|c|}
\hline \multicolumn{2}{|l|}{ Characteristic } & \multirow{2}{*}{$\begin{array}{l}\text { No of patient (\%) } \\
32(69.6)\end{array}$} \\
\hline Sex & Male & \\
\hline & Female & $14(30.4)$ \\
\hline \multirow[t]{6}{*}{ Location of defect } & Forefoot & $15(32.6)$ \\
\hline & Dorsum & $10(21.7)$ \\
\hline & Heel & $11(23.9)$ \\
\hline & Plantar & $2(4.3)$ \\
\hline & Ankle & $2(4.3)$ \\
\hline & Lateral malleolar & $6(13)$ \\
\hline \multirow[t]{3}{*}{ Comorbidity } & ESRD & $8(17.4)$ \\
\hline & Severe PAD & $23(50)$ \\
\hline & Smoking & $17(36.9)$ \\
\hline Infection & & $13(28.3)$ \\
\hline
\end{tabular}

Twenty-three patients (50\%) were diagnosed with severe PAD with grade 4 and 5 . Single-arterial stenosis was found in $9 / 23$ patients (39.1\%), double-arterial stenosis in $7 / 23$ patients $(30.4 \%)$ and triple-arterial stenosis in $7 / 23$ patients (30.4\%). All of severe PAD patients underwent PTA a couple of days before the free flap surgery. The mean interval between PTA procedure and free flap surgery was $15.43 \pm 12.28$ days, range from 4 to 54 days. Angioplasty failed in two cases consisted of one anterior tibial artery (ATA) among single-arterial stenosis patients and one posterior tibial artery (PTa) among triple-arterial stenosis patients. The post-angioplasty pedal arch was type 1 in $13 / 23$ patients (56.5\%), type $2 \mathrm{~A}$ and $2 \mathrm{~B}$ in $7 / 23$ and $2 / 23$ patients respectively and type 3 in only one patient (Table 4.). 
Table 4

Detail of vascular status of severe PAD group

\begin{tabular}{|c|c|c|c|c|c|}
\hline No & $\begin{array}{l}\text { Impaired } \\
\text { vessels }\end{array}$ & Angioplasty & $\begin{array}{l}\text { Interval } \\
\text { (days) }\end{array}$ & $\begin{array}{l}\text { Recipient } \\
\text { artery }\end{array}$ & $\begin{array}{l}\text { Type of pedal } \\
\text { arch }\end{array}$ \\
\hline 1 & ATA & ATA & 4 & ATA & 1 \\
\hline 2 & ATA, PTa & ATA, PTa & 32 & PTa & 1 \\
\hline 3 & ATA, PTa, PeA & ATA, PTa & 24 & ATA & 1 \\
\hline 4 & ATA, PTa & ATA, PTa & 12 & РTa & 1 \\
\hline 5 & PTa, PeA & PTa & 26 & ATA & $2 \mathrm{~A}$ \\
\hline 6 & ATA, PTa, PeA & ATA, PeA & 5 & ATA & $2 A$ \\
\hline 7 & ATA, PeA & ATA & 10 & ATA & 1 \\
\hline 8 & ATA & ATA & 7 & РTa & $2 \mathrm{~B}$ \\
\hline 9 & ATA & ATA & 35 & РТa & 1 \\
\hline 10 & ATA, PTa, PeA & ATA, PeA & 5 & ATA & $2 \mathrm{~A}$ \\
\hline 11 & ATA & ATA (fail) & 8 & ATA & $2 B$ \\
\hline 12 & ATA & ATA & 7 & ATA & 1 \\
\hline 13 & PTa & PTa & 8 & ATA & 1 \\
\hline 14 & ATA, PTa, PeA & ATA, PeA & 23 & ATA & $2 \mathrm{~A}$ \\
\hline 15 & PTa, PeA & PTa, PeA & 5 & ATA & $2 \mathrm{~A}$ \\
\hline 16 & ATA & ATA & 7 & ATA & 1 \\
\hline 17 & ATA, PTa, PeA & ATA, PTa & 14 & PTa & 1 \\
\hline 18 & ATA & ATA & 11 & ATA & 1 \\
\hline 19 & PTa, PeA & PeA & 19 & PTa & $2 \mathrm{~A}$ \\
\hline 20 & ATA, PTa & ATA, PTa & 7 & ATA & 1 \\
\hline 21 & ATA, PTa, PeA & ATA & 16 & ATA & $2 \mathrm{~A}$ \\
\hline 22 & ATA, PTa, PeA & $\begin{array}{l}\text { ATA, PTa (fail), } \\
\text { PeA }\end{array}$ & 54 & ATA & 3 \\
\hline 23 & ATA & ATA & 16 & ATA & 1 \\
\hline \multicolumn{6}{|c|}{ ATA $=$ Anterior tibial artery } \\
\hline \multicolumn{6}{|c|}{$\mathrm{PTa}=$ Posterior tibial artery } \\
\hline PeA & Peroneal artery & & & & \\
\hline
\end{tabular}


Two donor sites of free flap included anterolateral thigh (ALT) in 40 cases and medial sural artery perforator (MSAP) in 6 cases were used to cover the defects of foots. The flap size was ranged from $3 \times$ $5.5 \mathrm{~cm}$ to $12 \times 20 \mathrm{~cm}$. Recipient vessels were $13 \mathrm{PTa}, 33$ ATA and its branch included dorsalis pedis artery (DPA) and first dorsal metatarsal artery. Among them, 18 recipient arteries (39.1\%) were revascularized vessels. End-to-side method was done in 40 flaps (87\%) and end-to-end was in six flaps (13\%). 37 flaps had two veins and nine flaps had one vein only (Table 5.). Total flap necrosis was seen in five cases (10.9\%). Of these patients, two new ALT flaps were successfully replaced in two patients and the other patients were treated with additional debridement, VAC, and split thickness skin graft. The other complications included marginal necrosis (4 flaps), wound dehiscence (4 flaps) treated with simple closure or skin graft without any special event. During the perioperative period, there was no in-hospital mortality, however, two patients died 5 months and 7 months post-operation because of pneumonia and urinary tract infection respectively. No further major amputation had been required for all the follow-up period.

Table 5

Flap characteristics

\begin{tabular}{|lll|}
\hline Characteristic & & No. of patients (\%) \\
\hline \multirow{2}{*}{ Type of flap } & ALT & $40(87)$ \\
\cline { 2 - 3 } & MSAP & $6(13)$ \\
Arteriorrhaphy & E-E & $33(71.7)$ \\
\cline { 2 - 3 } & ATA & $13(28.3)$ \\
Eein & 1 & $6(13)$ \\
\cline { 2 - 3 } Complication & 2 & $40(87)$ \\
\cline { 2 - 3 } & Total flap necrosis & $5(10.9 \%)$ \\
\cline { 2 - 3 } & Marginal necrosis & $4(8.7 \%)$ \\
\cline { 2 - 3 } & Wound dehiscence & $4(8.7 \%)$ \\
\cline { 2 - 3 } & & $37(80.4)$ \\
\hline
\end{tabular}

Four of five total necrosis flaps were in patients with ESRD, analysis showed the significant association between ESRD and the flap failure $(p=0.002)$. There was no significant difference of the flap loss rate between the choices of flap, the types of arteriorrhaphy and using of revascularized recipient artery as well. The rate of total flap necrosis in patients who underwent PTA procedure because of severe PAD was not significantly higher than in patients without severe PAD. In the severe PAD group $(n=23)$, the rate of flap loss was significantly different between type 1 of pedal arch patients and the other types $(p=0.024)$. 
Among these patients, total flap necrosis is only found in patients with type 2 or 3 of the pedal arch (Table 6.).

Table 6

Chi-square analysis for flap success

\begin{tabular}{|c|c|c|c|c|}
\hline & & Flap total necrosis & Flap success & $p$ \\
\hline \multirow[t]{2}{*}{ ESRD } & ESRD & 4 & 4 & \multirow[t]{2}{*}{$0.002^{*}$} \\
\hline & No & 1 & 37 & \\
\hline \multirow[t]{2}{*}{ PAD } & Severe PAD & 4 & 19 & \multirow[t]{2}{*}{0.346} \\
\hline & Non- severe PAD & 1 & 22 & \\
\hline \multirow[t]{2}{*}{ Recipient arteries } & Revascularized & 3 & 15 & \multirow[t]{2}{*}{0.365} \\
\hline & Normal & 2 & 26 & \\
\hline \multirow{2}{*}{$\begin{array}{l}\text { Post-angioplasty pedal arch } \\
(\mathrm{n}=23)\end{array}$} & Type I & 0 & 13 & \multirow[t]{2}{*}{$0.024^{*}$} \\
\hline & Type II and III & 4 & 6 & \\
\hline \multicolumn{5}{|l|}{ * Statistically significant } \\
\hline \multicolumn{5}{|l|}{ Non-severe PAD = Grade 0-3 } \\
\hline Severe PAD $=$ Grade 4 and 5 & & & & \\
\hline
\end{tabular}

\section{Case Reports}

\section{Case 1}

A 53-year-old man with a 17-year history of diabetes and ESRD admitted for an unhealed wound over the dorsal of right foot. The anterior tibial arterial pulse was not palpable in the physical examination. CT angiogram revealed total occlusion of the ATA at the proximal level (Fig. 1). In angiography, the status of ATA was confirmed. Immediate balloon angioplasty was performed, ATA was successfully revascularized, and complete blood flow in the pedal arch was resumed. After serial debridement, the tendon and bone were exposed. An ALT flap with one perforator was used for soft-tissue coverage, and the newly patent ATA was selected as the recipient artery and the recipient veins were concomitant veins. Arterial anastomosis and venous anastomosis were performed in end-to-side and end-to-end manner, respectively. No postoperative complications were noted, and a 4-month follow-up revealed a well-healing, well-perfused free flap. The patient was able to ambulate with no complaints.

Figure 1. (a) A chronic wound of dorsal foot. (b)(c) Anterior tibial artery was totally occluded, preoperative angiography indicated the type 2B of the pedal arch. (d) Anterior tibial artery was successfully 
revascularized, the foot was supplied by both dorsal pedis artery and plantar artery. (e) ALT free flap. (f) One day after operation. (g) 4 month post-operation.

\section{Case 2}

A 55-year-old man with a 20-year history of diabetes presented with diabetic gangrene on his 5 th toe. Serial debridement and amputation were performed and free tissue transfer was considered for covering 5th metatarsal bone (Fig. 2). Preoperative angioplasty indicated the absence of blood flow from the PTa to the pedal arch because of total occlusion. He underwent balloon angioplasty of the left PTa and plantar artery. After angioplasty, complete pedal arch was seen with the supply from both DPA and the plantar artery. Eight days after revascularization, an ALT flap was harvested and anastomosed to the ATA in an end-to-side manner. No additional surgery was required, and a 4-years follow-up revealed a wellhealing, well-perfused free flap without another wound.

Figure 2. (a) Soft-tissue defect with 5th metatarsal bone exposure. (b) Angiography showed total occlusion of posterior tibial artery and plantar artery. (c) Complete pedal arch (type 1) was seen postangioplasty. (d) $13 \times 9 \mathrm{~cm}$ ALT flap was performed. (e) 2 days post-operation. (f) 4 years follow-up.

\section{Discussion}

Recently, numerous studies have showed that extensive DM foot ulcer could be safely treated with free flap transfer [8-10]. A systematic review study based on 18 studies of free tissue transfer for ischemic lower limb wound coverage showed a high rate of free flap survival as $92 \%$ and limb salvage rate of 83.4\% [11]. In 1985 Briggs et al. firstly described the concept of combining vascular bypass surgery and free tissue transfer which could effectively manage the ischemic limbs as well as covered the complex defects [4]. This method expressively increased the salvage rate of the critical ischemic diabetic limb. Subsequently, several studies on combination between vascular distal bypass surgery and free flap transfer have been performed [12-15]. Although bypass surgery was successfully used for chronic limb ischemia management earlier on, PTA has slowly superseded open surgical bypass because of its advantages included reducing complication and length of hospitalization, feasible in elder and patients with poor general condition or even in patients with severe multi-segmental occlusive disease [16-18]. In addition, with the introduction of small-scale balloon and drug-coated balloon, PTA is significantly effective with better primary patency and low rate of restenosis [19]. Our institute has recently employed PTA as the first-line treatment for infrainguinal PAD patients. In the present study, we combined PTA and free flap surgery for the ischemic chronic wounds in diabetic patients and the overall flap survival rate was $89.1 \%$ comparable to the previous studies. Although the flap survival rate and limb salvage rate were relatively high, Oh et al. reported some obstacle factors included PAD, history of previous angioplasty and using immunosuppressive agents after renal transplant [20]. Authors emphasized that PAD and having a history of angioplasty had a significantly higher risk of flap failure (17.59 times and 10.212 times respectively). Twenty-three patients in our study were grade 4 and 5 PAD patients with severe stenosis in at least one main of infrapopliteal arteries. Though four of five flaps loss were among severe PAD patients, the analysis showed no significant difference between the severe PAD patients and the other 
patients. All of the severe PAD patients in this study underwent PTA before the flap transfer surgery to achieve the straight-line blood flow to the pedal arch, however, we failed to reconstruct the pedal arch in one patient classified as type 3. Despite having no impact on to amputation rate, the quality of pedal arch had affected the rate of wound healing and time to healing as well [7, 21]. In this series, we also found the crucial influence of quality of pedal arch to the free flap survival. Among 13 patients with complete final pedal arch after PTA procedure, there was no flap necrosis, while four flaps loss were found in the group of ten patients with compromised pedal arch.

Hong stated that the evaluation of recipient arteries perfusion and identification of an appropriate vessel may be the major challenge in reconstructive microsurgery [3]. Previous literatures showed that the appropriate recipient artery could be selected preoperatively via angiography or CT angiography images $[6,22,23]$. In addition, Kim et al. employed Doppler ultrasonography to check the recipient artery and demonstrated that over $40 \mathrm{~cm} / \mathrm{s}$ of peak blood flow velocity (PBFV) should be achieved to assure the success in free tissue transfer [24]. Nevertheless, it was indicated that pre-operation blood flow measurement may not be similar to actual findings in surgery [3]. In our institute, we did not measure PBFV before the surgery but we preferred using CT angiography as a minimally invasive modality for vascular status assessment and flap planning as well. However, the final decision must be made based on the intraoperative condition of the arteries. The surgery would be abandoned if no sufficient vessel were found.

Based on the evidence of the safe utility of revascularized recipient artery, we also anastomosed the flaps to 18 arteries that had undergone PTA $[22,25]$. Although three of 18 flaps totally necrosed, no significant correlation was found between the revascularized recipient artery and the flap loss rate.

End-to-side anastomosis was performed in 40 flaps because it was believed that preservation of major arteries had been very important in CLI patients. In addition, the flaps were also occasionally supplied by the retrograde blood flow, especially in case of intact pedal arch. Lee et al. found a significantly lower risk of wound complication of end-to-side anastomosis rather than end-to-end when they performed a study of factors affect the flap survival and complication [9]. Though heavy calcification of the arterial walls was common in PAD patients, we always tried to find the least atherosclerotic for anastomosis. The endto-end modality would only be used if we could not find less diseased area or unsatisfied result after endto-side anastomosis.

There was no consensus in using fasciocutaneous or muscle flap combined with skin graft. We believed that fasciocutaneous was sufficient for the diabetic foot ulcers often thin and superficial. In this study, ALT was our most common flap and MSAP flap was used as an alternative especially for the forefoot and small defects. However, because medial sural artery is considered as an important collateral around the knee, the MSAP flap should be avoided in order to prevent the further limb damage in patient with occlusion of popliteal artery [26, 27].

\section{Conclusions}


The diabetic foot ulcer always challenges surgeons because of prevalence of comorbidities, infection, neuropathy and vasculopathy. These chronic ischemic wounds are able to reconstruct with the combination of endovascular intervention and free flap. Our study found a significant association between the quality of post-angioplasty pedal arch and flap success rate. The endovascular intervention should aim to achieve the complete pedal arch not only for improvement of wound healing but also for optimal result of free flap.

\section{Abbreviations}

PAD: peripheral arterial disease; DM: diabetes mellitus; PTA: percutaneous transluminal angioplasty; ESRD: end-stage renal disease; ATA: anterior tibial artery; DPA: dorsal pedis artery; PTa: posterior tibial artery; ALT: anterolateral thigh; MSAP: medial sural artery perforator; PBFV: peak blood flow velocity.

\section{Declarations}

\section{Ethical approval}

This study was approved by the Institutional Review Board of Ajou Medical Center (AJIRB-MED-MDB-20374).

\section{Consent for publication}

Not applicable.

\section{Availability of data and materials}

Please contact the corresponding author for data request.

\section{Competing interests}

The authors declare that they have no competing interests.

\section{Funding}

Not applicable.

\section{Author's contributions}

Conception and design: IJL. Data collection: DHL, DQT, WBL. Analysis and interpretation: DQT. HMH, DHL, WBL. Writing article: DQT. Critical revision of the article: HMH, IJL. Final approval of the article: all authors.

\section{Acknowledgement}

Not applicable. 


\section{References}

1. Moulik PK, Mtonga R, Gill GV. Amputation and mortality in new-onset diabetic foot ulcers stratified by etiology. Diabetes Care. 2003;26(2):491-4.

2. Bordianu A, Bobirca F, Patrascu T. Skin Grafting in the Treatment of Diabetic Foot Soft Tissue Defects. Chirurgia (Bucur). 2018;113(5):644-50.

3. Hong JP, Oh TS. An algorithm for limb salvage for diabetic foot ulcers. Clin Plast Surg. 2012;39(3):341-52.

4. Briggs SE, Banis JC Jr, Kaebnick H, Silverberg B, Acland RD. Distal revascularization and microvascular free tissue transfer: an alternative to amputation in ischemic lesions of the lower extremity. J Vasc Surg. 1985;2(6):806-11.

5. Huang CC, Chang $\mathrm{CH}$, Hsu H, Mark Chiu CH, Lin CM, Lee JT, et al. Endovascular revascularization and free tissue transfer for lower limb salvage. J Plast Reconstr Aesthet Surg. 2014;67(10):1407-14.

6. Mishra A, Jain N, Bhagwat A. CT Angiography of Peripheral Arterial Disease by 256-Slice Scanner: Accuracy, Advantages and Disadvantages Compared to Digital Subtraction Angiography. Vasc Endovascular Surg. 2017;51(5):247-54.

7. Kawarada O, Fujihara M, Higashimori A, Yokoi Y, Honda Y, Fitzgerald PJ. Predictors of adverse clinical outcomes after successful infrapopliteal intervention. Catheter Cardiovasc Interv. 2012;80(5):86171.

8. Hashimoto I, Abe Y, Morimoto A, Kashiwagi K, Goishi K, Nakanishi H. Limb salvage and vascular augmentation by microsurgical free flap transfer for treatment of neuropathic diabetic foot ulcers. $J$ Med Invest. 2014;61(3-4):325-32.

9. Lee ZH, Daar DA, Stranix JT, Anzai L, Levine JP, Saadeh PB, et al. Free-Flap Reconstruction for Diabetic Lower Extremity Limb Salvage. J Surg Res. 2020;248:165-70.

10. Kolbenschlag J, Hellmich S, Germann G, Megerle K. Free tissue transfer in patients with severe peripheral arterial disease: functional outcome in reconstruction of chronic lower extremity defects. $J$ Reconstr Microsurg. 2013;29(9):607-14.

11. Fitzgerald OConnor EJ, Vesely M, Holt PJ, Jones KG, Thompson MM, Hinchliffe RJ. A systematic review of free tissue transfer in the management of non-traumatic lower extremity wounds in patients with diabetes. Eur J Vasc Endovasc Surg. 2011;41(3):391-9.

12. Randon $C$, Vermassen F, Jacobs B, De Ryck F, Van Landuyt $K$, Taes $Y$. Outcome of arterial reconstruction and free-flap coverage in diabetic foot ulcers: long-term results. World J Surg. 2010;34(1):177-84.

13. Igari K, Kudo T, Toyofuku T, Jibiki M, Inoue $Y$, Tanaka $K$, et al. Combined arterial reconstruction and free tissue transfer for patients with critical limb ischemia. Ann Vasc Dis. 2013;6(4):706-10.

14. Vermassen FE, van Landuyt K. Combined vascular reconstruction and free flap transfer in diabetic arterial disease. Diabetes Metab Res Rev. 2000;16(Suppl 1):33-6. 
15. Kallio M, Vikatmaa P, Kantonen I, Lepantalo M, Venermo M, Tukiainen E. Strategies for free flap transfer and revascularisation with long-term outcome in the treatment of large diabetic foot lesions. Eur J Vasc Endovasc Surg. 2015;50(2):223-30.

16. Arvela E, Venermo M, Soderstrom M, Korhonen M, Halmesmaki K, Alback A, et al. Infrainguinal percutaneous transluminal angioplasty or bypass surgery in patients aged 80 years and older with critical leg ischaemia. Br J Surg. 2011;98(4):518-26.

17. Patel SD, Biasi L, Paraskevopoulos I, Silickas J, Lea T, Diamantopoulos A, et al. Comparison of angioplasty and bypass surgery for critical limb ischaemia in patients with infrapopliteal peripheral artery disease. Br J Surg. 2016;103(13):1815-22.

18. Kudo T, Chandra FA, Ahn SS. The effectiveness of percutaneous transluminal angioplasty for the treatment of critical limb ischemia: a 10-year experience. J Vasc Surg. 2005;41(3):423-35. discussion 35.

19. Tepe G, Laird J, Schneider P, Brodmann M, Krishnan P, Micari A, et al. Drug-coated balloon versus standard percutaneous transluminal angioplasty for the treatment of superficial femoral and popliteal peripheral artery disease: 12-month results from the IN.PACT SFA randomized trial. Circulation. 2015;131(5):495-502.

20. Oh TS, Lee HS, Hong JP. Diabetic foot reconstruction using free flaps increases 5-year-survival rate. J Plast Reconstr Aesthet Surg. 2013;66(2):243-50.

21. Rashid H, Slim H, Zayed H, Huang DY, Wilkins CJ, Evans DR, et al. The impact of arterial pedal arch quality and angiosome revascularization on foot tissue loss healing and infrapopliteal bypass outcome. J Vasc Surg. 2013;57(5):1219-26.

22. Janhofer DE, Lakhiani C, Kim PJ, Akbari C, Naz I, Tefera EA, et al. The Utility of Preoperative Arteriography for Free Flap Planning in Patients with Chronic Lower Extremity Wounds. Plast Reconstr Surg. 2019;143(2):604-13.

23. Park SW, Kim J, Choi J, Kim JS, Lee JH, Park YS. Preoperative Angiographic Criteria for Predicting Free-Flap Transfer Outcomes in Patients With Lower-Extremity Peripheral Arterial Disease. Int J Low Extrem Wounds. 2016;15(4):325-31.

24. Kim JY, Lee YJ. A study of the survival factors of free flap in older diabetic patients. J Reconstr Microsurg. 2007;23(7):373-80.

25. Hahn HM, Jeong YS, Hong YS, Won JH, Lim SH, Kim J, et al. Use of revascularized artery as a recipient in microvascular reconstruction of the lower leg: An analysis of 62 consecutive free flap transfers. J Plast Reconstr Aesthet Surg. 2017;70(5):606-17.

26. Ozkan H, Irkoren S, Aydin O. Applicability of medial sural artery perforator flap in patients with diabetes with peripheral arterial disease for complex lower extremity defects. Turkish Journal of Plastic Surgery. 2018;26(3).

27. De Luccia N, Sassaki P, Durazzo A, Sandri G, Kikuchi M, Hirata C, et al. Limb salvage using bypass to the perigeniculate arteries. Eur J Vasc Endovasc Surg. 2011;42(3):374-8. 


\section{Figures}

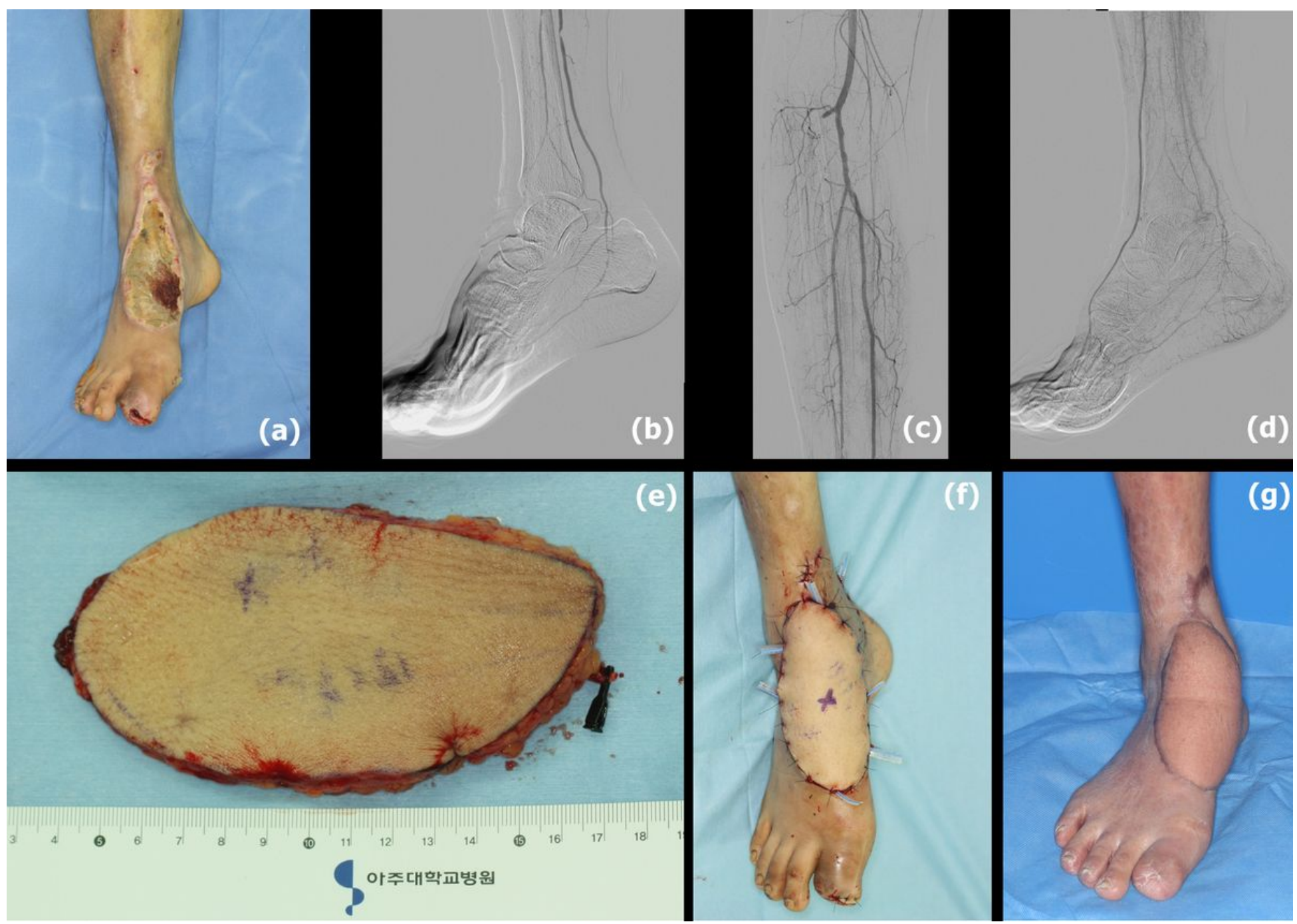

\section{Figure 1}

(a) A chronic wound of dorsal foot. (b)(c) Anterior tibial artery was totally occluded, pre-operative angiography indicated the type $2 \mathrm{~B}$ of the pedal arch. (d) Anterior tibial artery was successfully revascularized, the foot was supplied by both dorsal pedis artery and plantar artery. (e) ALT free flap. (f) One day after operation. (g) 4 month post-operation. 


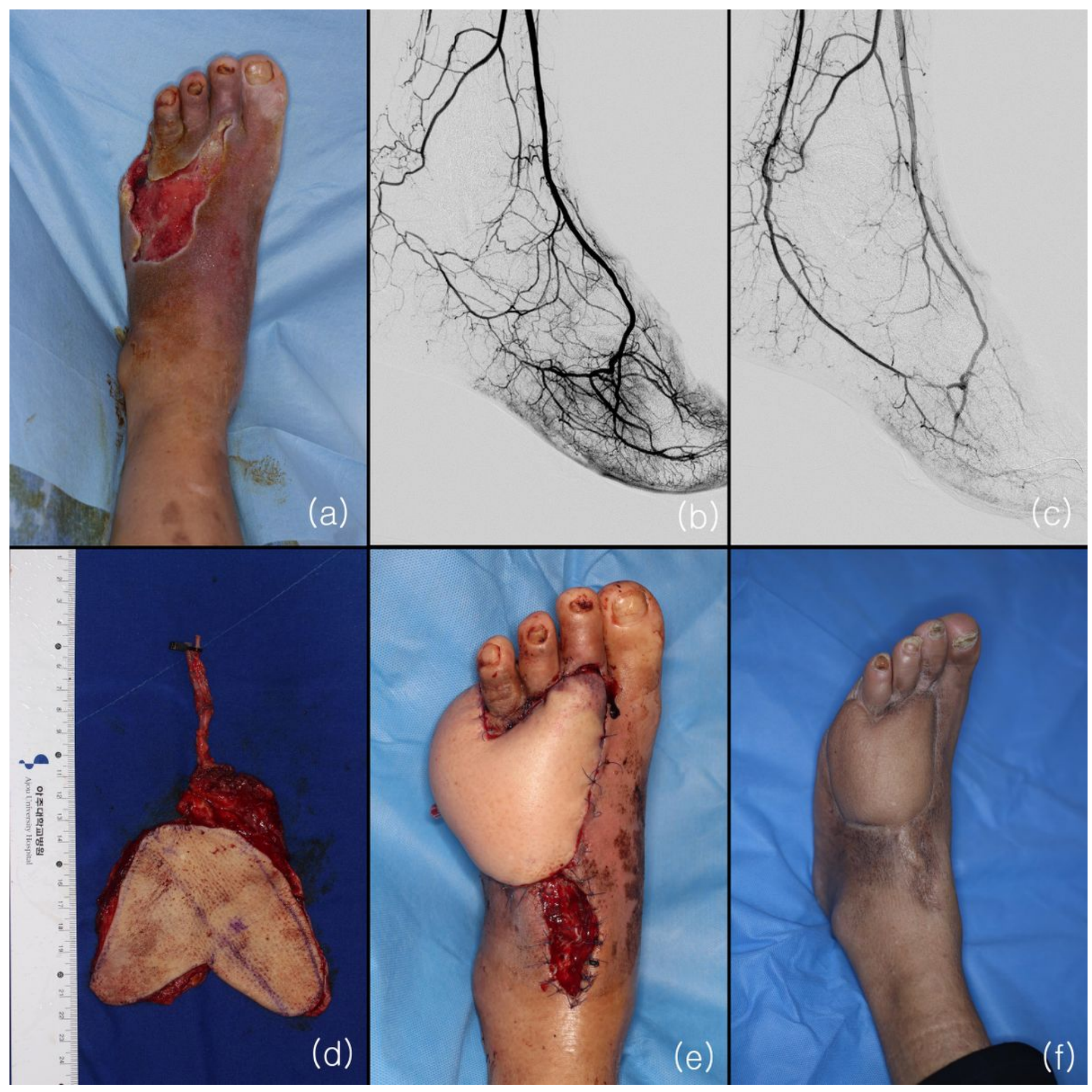

Figure 2

(a) Soft-tissue defect with 5th metatarsal bone exposure. (b) Angiography showed total occlusion of posterior tibial artery and plantar artery. (c) Complete pedal arch (type 1) was seen post-angioplasty. (d) $13 \times 9 \mathrm{~cm}$ ALT flap was performed. (e) 2 days post-operation. (f) 4 years follow-up. 